\title{
Permafrost temperature and active-layer thickness of Yakutia with 0.5-degree spatial resolution for model evaluation
}

\author{
C. Beer ${ }^{1,2}$, A. N. Fedorov ${ }^{3,4}$, and Y. Torgovkin ${ }^{3}$ \\ ${ }^{1}$ Max Planck Institute for Biogeochemistry, Jena, Germany \\ ${ }^{2}$ Department of Applied Environmental Science (ITM) and the Bert Bolin Centre for Climate Research, \\ Stockholm University, Stockholm, Sweden \\ ${ }^{3}$ Melnikov Permafrost Institute SB RAS, Yakutsk, Russia \\ ${ }^{4}$ International Center BEST, North-Eastern Federal University, Yakutsk, Russia \\ Correspondence to: C. Beer (christian.beer@itm.su.se)
}

Received: 20 February 2013 - Published in Earth Syst. Sci. Data Discuss.: 27 May 2013

Revised: 29 August 2013 - Accepted: 3 September 2013 - Published: 24 September 2013

\begin{abstract}
Based on the map of landscapes and permafrost conditions in Yakutia (Merzlotno-landshaftnaya karta Yakutskoi0 ASSR, Gosgeodeziya SSSR, 1991), rasterized maps of permafrost temperature and activelayer thickness of Yakutia, East Siberia were derived. The mean and standard deviation at 0.5-degree grid cell size are estimated by assigning a probability density function at 0.001 -degree spatial resolution. The gridded datasets can be accessed at the PANGAEA repository (doi:10.1594/PANGAEA.808240). Spatial pattern of both variables are dominated by a climatic gradient from north to south, and by mountains and the soil type distribution. Uncertainties are highest in mountains and in the sporadic permafrost zone in the south. The maps are best suited as a benchmark for land surface models which include a permafrost module.
\end{abstract}

\section{Introduction}

Physical and biogeochemical processes in landscapes with underling permafrost in high latitudes are important components of the Earth system. This importance has led to recent advancements of heat conduction and phase change representations in land surface schemes of Earth system models (Lawrence and Slater, 2005; Koven et al., 2009, e.g.,). These models calculate the physical and biogeochemical state of the ecosystem for large grid cells (approximate 0.5 to 3.75 degree spatial resolution) by using soil texture and land cover information as well as climate data from the atmospheric component of the Earth system model or from observationbased datasets, such as reanalysis products. For instance, these 1-D models simulate a mean soil temperature profile as a result of air temperature forcing on top of the soil, snow and organic layer insulation, and soil moisture, organic matter and soil texture type impacts on thermal diffusivity. These models are to be used to project future ecosystem states un- der global change including the effects of thawing permafrost on vegetation functions and carbon dioxide and methane production from carbon-rich permafrost soils.

In global models, big assumptions are made about initialization of state variables, such as soil temperature, and about parameter values, such as snow thermal parameters. Therefore, the validation of the simulation of recent permafrost state variables, such as permafrost temperature or active-layer thickness is an important step before projecting future conditions. For doing so, comparisons to databases of point measurements, such as GTN-P (Romanovsky et al., 2010b) or CALM (Brown et al., 2000) are powerful tools (Oelke et al., 2003; Beer et al., 2007; Lawrence et al., 2008, e.g.,). However, for such point-wise comparisons the models should be run using site-level soil texture type information and site-level meteorological observations, which is an enormous effort for a large set of sites, such as represented by CALM. In addition, the comparison of a large-scale temperature value representing a mean for an 0.5-degree grid cell 
with a single measurement inside that grid cell is highly unreliable since local conditions and processes, such as the horizontal water flow are usually not represented by a site-level run of a global model. Therefore, the assignment of typical ranges of permafrost temperature and active-layer thickness (ALT) for certain landscape characteristics is a first useful generalization of the observations. It also allows a detailed mapping of such ranges from which one can scale to large grid cells representing, for example, 0.5 degrees $\times 0.5$ degrees. Permafrost temperature is defined as the soil temperature in the depth where temperature fluctuations are negligible, usually 10-20 m. Active-layer thickness (ALT) stands for the maximum thawing depth at the end of the thawing season.

One important map in this context is the map of landscapes and permafrost conditions in Yakutia (Merzlotnolandshaftnaya karta Yakutskoi0 ASSR, Gosgeodeziya SSSR, 1991) (Fedorov et al., 1989, 1991; Beer et al., 2013). It represents permafrost landscape conditions with a scale of $1: 2500000$, as an average during 1960-1987. The map covers Yakutia which is a huge area within the Siberian permafrost zone. Therefore, the information about permafrost state variables stored in this map is a useful for the initialization of land surface and ecosystem models or can be used for a validation of model results. This information from East Siberia is also complementary to the high density of data points in Alaska in the CALM and GTN-P databases. In this paper, we use the information stored in this map to scale permafrost and subsoil temperature, and ALT to 0.5-degree spatial resolution for subsequent comparisons to model results.

\section{Methods}

Several features of the map of landscapes and permafrost conditions in Yakutia (Fedorov et al., 1989, 1991) (Merzlotno-landshaftnaya karta Yakutskoi0 ASSR, Gosgeodeziya SSSR, 1991) were digitized and the respective GIS vector data reprojected to plain latitude/longitude. For deriving permafrost temperature and active-layer thickness (ALT), the two layers describing (i) surface deposit, and (ii) describing vegetation and permafrost type are used. The surface deposit layer is displayed in hachures in the original map (see original map including the legend in Supplement). In the original legend, surface deposit information is given by rows. The layer describing vegetation and permafrost type is represented by color (columns in the legend) in the original map. These layers have been digitized individually and the respective polygons were further rasterized with 0.001degree spatial resolution. Visual comparison with the vector data has proven to be an accurate and full representation of all polygons using such high resolution. Then, these two types of information were combined for assigning permafrost temperature and ALT according to the map legend at the full 0.001-degree spatial resolution. For each represented combi- nation of the GIS layers, ranges of permafrost temperature and active-layer thickness are given in the legend (cf. Supplement).

The legend usually indicates a common range and a most frequent range of temperature and ALT for combinations of soil type and permafrost type. We calculate the mean value using the two indicators for the most frequent range of values and also interpret this range as the standard deviation. Then, we approximate a normal distribution by 100 random values representing the probability density function with that mean and standard deviation. In some cases, the values for the total possible range of values from the map legend do not exactly follow a normal distribution. Then, all of the randomly selected 100 data points along the density function which are out of the reported possible range are discarded. In summary, this step gives 100 values for each of the 0.001 degree pixels of the original map representing a normal distribution of permafrost temperature, and another 100 values for representing the ALT distribution.

For scaling to 0.5-degree grid cell size, all 100-element vectors of the 0.001-degree pixels belonging to one 0.5degree pixel are combined to one unique vector. This latter big vector is used for estimating the mean and standard deviation of either permafrost temperature or ALT.

In some cases, only one range for permafrost temperature or ALT is reported instead of two ranges. To be most conservative, we define standard deviation as this full range. At the same time, the distribution is cut at these values. This approach ensures a high uncertainty of the values in the respective landscapes but also avoid the contribution of unrealistic values to the calculation of the overall mean and standard deviation for the 0.5-degree pixel.

In the case of discontinuous permafrost or sporadic permafrost landscapes, the legend indicates a permafrost temperature range in concert with a subsoil temperature range for non-permafrost areas. In this case, two temperature distributions were approximated, for permafrost and non-permafrost areas. Assuming $75 \%$ permafrost cover and $25 \%$ permafrost cover for discontinuous and sporadic permafrost landscapes, respectively, the two data vectors for temperature and the two data vectors for ALT hold either 75 or 25 data points. Then, all the individual vectors belonging to the 0.5 -degree grid cell are combined to one unique vector.

With the scaling methods described in this section we make sure to produce a subsoil temperature map and a ALT map that are most comparable with global modelling results.

\section{Results and discussion}

Figure 1a shows subsoil temperature (permafrost temperature in continuous permafrost zone and mainly permafrost temperature in discontinuous permafrost zone) with 0.5degree spatial resolution. These values represent the mean for each grid cell during 1960-1987. Values range between 


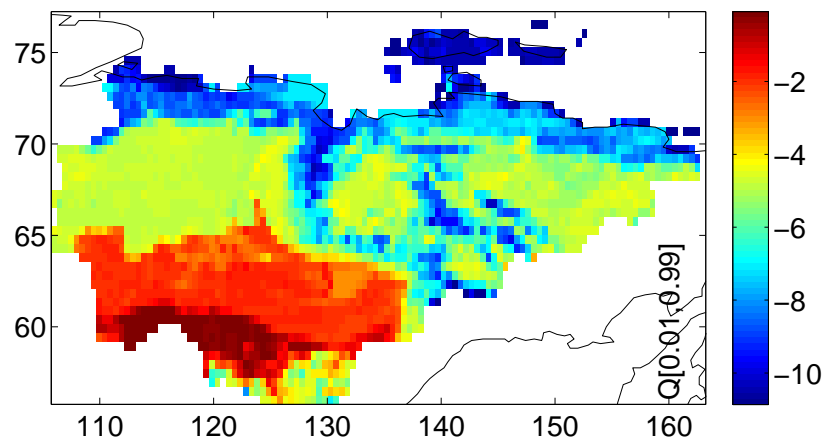

(a) Mean of subsoil temperature

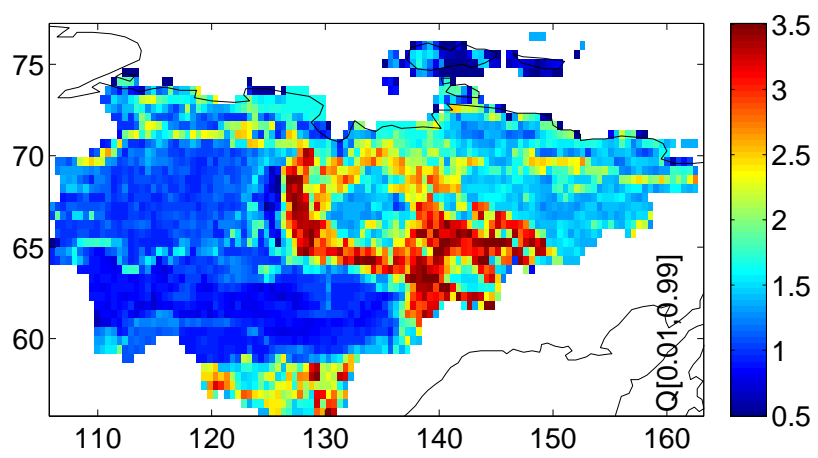

(b) Standard deviation of subsoil temperature

Figure 1. Subsoil temperature. Shown are (0.01,0.99)-quantile ranges of mean and standard deviation from several soil and permafrost types within a 0.5 -degree grid cell.

-11 and $-0.3{ }^{\circ} \mathrm{C}$ from north to south. Only some sporadic permafrost areas in the south show slight positive subsoil temperatures. However, there are also clear longitudinal differences reflecting different climate regimes in mountains versus lowlands, in particular east of the river Lena. Figure $1 \mathrm{~b}$ shows that with a standard deviation of more than $3{ }^{\circ} \mathrm{C}$, the uncertainties in these mountains are also highest.

The huge range of subsoil temperature reflects the different climatic conditions and landscape types of Yakutia which were also the basis for defining the region as a IGBP transect (McGuire et al., 2002). These environmental conditions are also the reason for specific ecosystem types from tundra in the north to larch-dominated taiga in the south. Therefore, the region is useful for a validation of a global model (Sazonova et al., 2004).

Figure 2 shows a cross comparison of 0.5-degree pixellevel results of subsoil temperature (Fig. 1) to mean annual ground temperature measurements at a station inside the respective grid cell reported by the GTN-P database (Burgess et al., 2000; Romanovsky et al., 2010a). A comparison of station data to grid cell values from the high-resolution map (0.001-degree pixel size) was not possible since longitude and latitude values are stored with a low precision (second

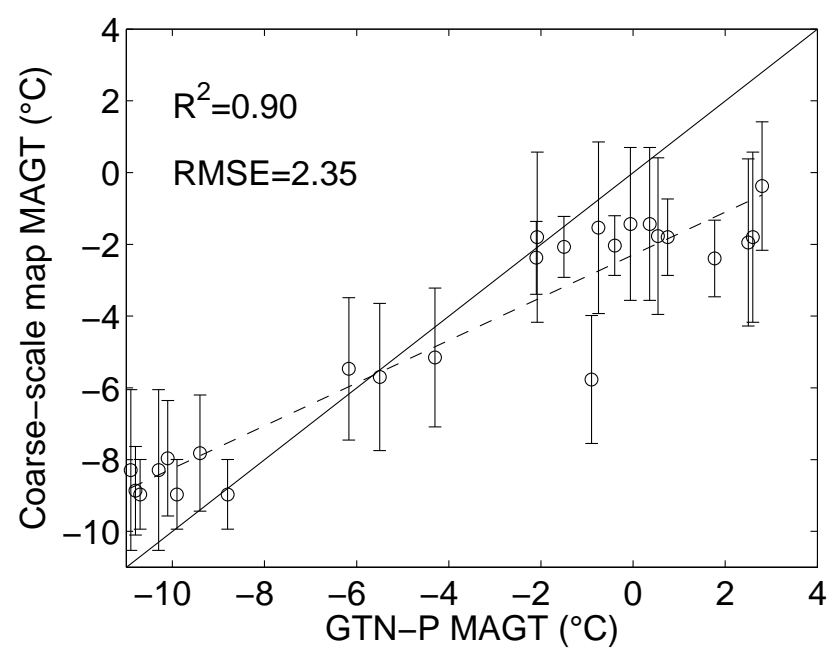

Figure 2. Cross comparison of mean annual ground temperature (MAGT) in ${ }^{\circ} \mathrm{C}$ from the GTN-P databse and from the respective 0.5-degree grid cells extracted from the map presented in (Fig. 1).

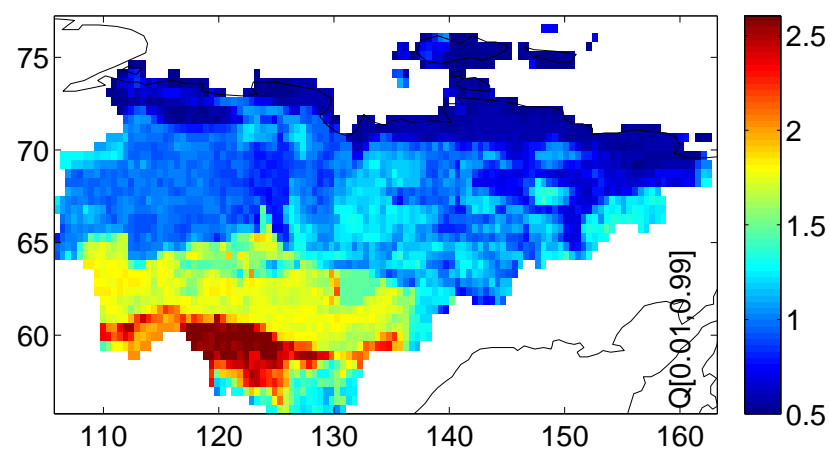

(a) Mean of active-leayer thickness

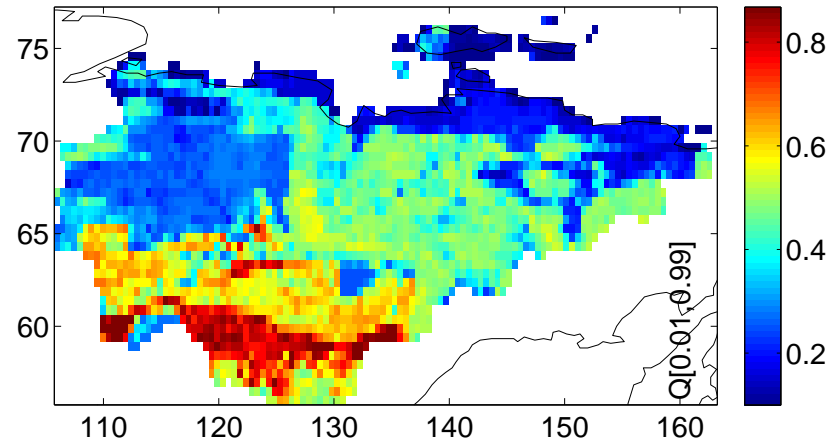

(b) Standard deviation of active-leayer thickness

Figure 3. Active-layer thickness. Shown are $(0.01,0.99)$-quantile ranges of mean and standard deviation from several soil and permafrost types within a 0.5 -degree grid cell. 


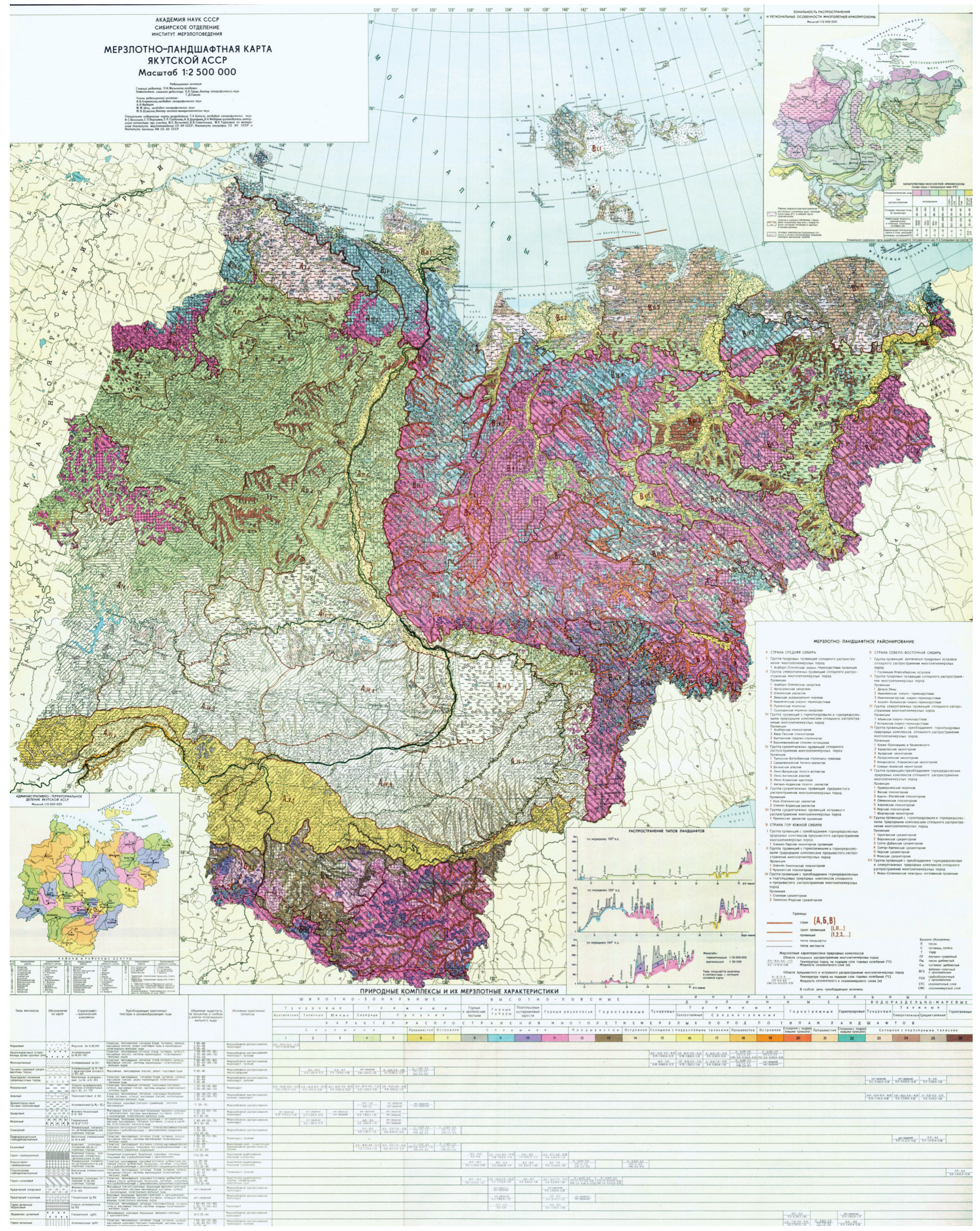

Figure A1. Original map of landscapes and permafrost conditions in Yakutia (Fedorov et al., 1989, 1991). 


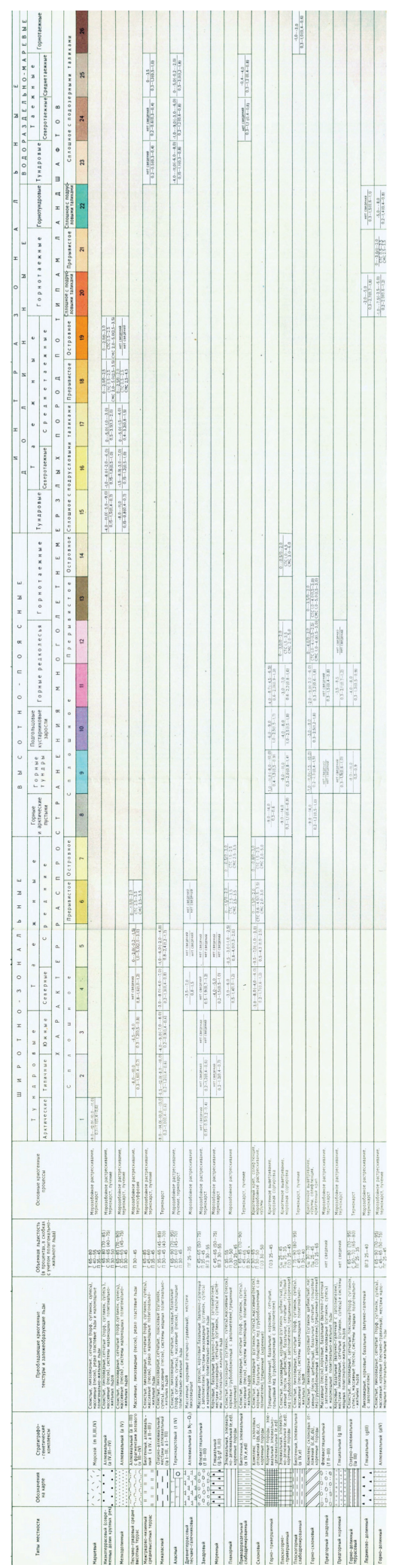

Figure A2. Legend of the original map of landscapes and permafrost conditions in Yakutia. decimal place). However, the spatial sub-grid variability is partly represented by the standard deviation (Fig. 1b) and also reported in Fig. 2. The cross comparison shows that the 0.5 -degree map represents the general temperature range and spatial pattern. The coefficient of determination is high (0.9) and the root mean square error is small $\left(2.4^{\circ} \mathrm{C}\right)$. Usually, the temperature reported by GTN-P is within the mean \pm standard deviation of the coarse grid cells. There is a general overestimation of very cold temperatures $\left(<-10^{\circ} \mathrm{C}\right)$ and an underestimation of warm temperatures higher than zero ${ }^{\circ} \mathrm{C}$. We expect the scale mismatch between site data and our 0.5 degree grid cell results to be the main reason for such differences.

Active-layer thickness spatial patterns follow temperature patterns (Fig. 3a). Maximum thaw depth in summer can be very shallow north of $70^{\circ} \mathrm{N}(0.3-0.6 \mathrm{~m})$ but also quite deep south of $65^{\circ} \mathrm{N}$ and west of $136^{\circ} \mathrm{E}(1.5-2.7 \mathrm{~m})$. Between $65^{\circ} \mathrm{N}$ and $70^{\circ} \mathrm{N}$ or west of $136^{\circ} \mathrm{E}$, ALT usually varies between 0.6 and $1.4 \mathrm{~m}$. Uncertainty of ALT increases with ALT and is highest (up to $1 \mathrm{~m}$ ) in the south (Fig. 3b). The ALT map is unique in terms of spatial extend and ALT range and therefore very useful for a comparison with global or regional models.

ALT in discontinuous and sporadic permafrost zones are still not completely comparable to modeling results since the mapped data represents the ALT of the permafrost areas within the landscape while the global model usually simulates one mean soil temperature profile from which ALT is further derived. Therefore, the comparison of subsoil temperature should have higher priority in discontinuous and sporadic permafrost zones.

Uncertainty, expressed as standard deviation, increases to the south because of the occurrence of discontinuous and sporadic permafrost landscapes. The uncertainty information is most important for a comparison with global model results because it is an indicator for the spatial variability within the 0.5 -degree pixel.

This paper presents mean and standard deviation of subsoil temperature and ALT (Figs. 1 and 3). In doing so, our assumptions are compatible with assumption of other approaches for estimating coarse-scale patterns of permafrost temperature and ALT, such as process-oriented 1-D models. Therefore, model results can be directly compared to the maps presented in Figs. 1 and 3. However, the distribution of the quantities within each coarse-scale grid cell does not need to be normal. Skewed or multi-modal distributions can be expected from merging fine-scale results representing distinct landscape classes. Therefore, median and median absolute deviation as well as modes will be also computed for specific requests from the scientific community. 


\section{Summary}

This paper presents a map of permafrost temperature and a map of active-layer thickness of Yakutia, East Siberia at 0.5degree grid cell size. A detailed scaling from 0.001-degree raster images to 0.5 -degree maps using probability density approximations allows a spatial mean and standard deviation that are most useful for a comparison with results from land surface models which represent heat conduction and phase change. The gridded datasets can be accessed at the PANGAEA repository (doi:10.1594/PANGAEA.808240). In general, there is a strong north-south gradient of both subsoil temperature and active-layer thickness. However, mountains and soil types distributions lead to also more detailed longitudinal pattern. Uncertainties are highest in mountains and in the sporadic permafrost zone in the south.

Acknowledgements. Mean annual ground temperature data at a number of GTN-P sites in Russia are downloaded from the internet (http://www.gtnp.org) for a cross-comparison study.

Edited by: D. Carlson

\section{References}

Beer, C., Lucht, W., Gerten, D., Thonicke, K., and Schmullius, C.: Effects of soil freezing and thawing on vegetation carbon density in Siberia: A modeling analysis with the Lund-Potsdam-Jena Dynamic Global Vegetation Model (LPJ-DGVM), Global Biogeochem. Cy., 21, GB1012, doi:10.1029/2006GB002760, 2007.

Beer, C., Fedorov, A. N., and Torgovkin, Y.: Maps of subsoil temperature and active layer depth of Yakutian ASSR (Autonomous Soviet Socialist Republic of the Soviet Union), doi:10.1594/PANGAEA.808240, 2013.

Brown, J., Hinkel, K., and Nelson, F.: The circumpolar active layer monitoring (calm) program: Research designs and initial results 1, Polar Geogr., 24, 166-258, doi:10.1080/10889370009377698, 2000.

Burgess, M., Smith, S., Brown, J., Romanovsky, V., and Hinkel, K.: The Global Terrestrial Network for Permafrost (GTNet-P): permafrost monitoring contributing to global climate observations, Current Research 2000-E14, 2000.
Fedorov, A. N., Botulu, T. A., and Varlamov, S. P.: Permafrost Landscape of Yakutia (in Russian), Novosibirsk: GUGK, 1989.

Fedorov, A. N., Botulu, T. A., and Varlamov, S. P.: Permafrost Landscape Map of YYakutia ASSR, Scale 1:2500000, Moscow: GUGK, 1991.

Koven, C., Friedlingstein, P., Ciais, P., Khvorostyanov, D., Krinner, G., and Tarnocai, C.: On the formation of high-latitude soil carbon stocks: Effects of cryoturbation and insulation by organic matter in a land surface model, Geophys. Res. Lett., 36, L21501, doi:10.1029/2009GL040150, 2009.

Lawrence, D. and Slater, A.: A projection of severe near-surface permafrost degradation during the 21st century, Geophys. Res. Lett., 32, L24401, doi:10.1029/2005GL025080, 2005.

Lawrence, D., Slater, A., Romanovsky, V., and Nicolsky, D.: Sensitivity of a model projection of near-surface permafrost degradation to soil column depth and representation of soil organic matter, J. Geophys. Res., 113, F02011, doi:10.1029/2007JF000883, 2008.

McGuire, A., Wirth, C., Apps, M., Beringer, J., Clein, J., Epstein, H., Kicklighter, D., Bhatti, J., Chapin, F., de Groot, B., Efremov, D., Eugster, W., Fukuda, M., Gower, T., Hinzman, L., Huntley, B., Jia, G., Kasischke, E., Melillo, J., Romanovsky, V., Shvidenko, A., Vaganov, E., and Walker, D.: Environmental variation, vegetation distribution, carbon dynamics and water/energy exchange at high latitudes, J. Veg. Sci., 13, 301-314, 2002.

Oelke, C., Zhang, T., Serreze, M. C., and Armstrong, R. L.: Regional-scale modelling of soil freeze/thaw over the Artic drainage basin, J. Geophys. Res., 108, 4314, doi:10.1029/2002JD002722, 2003.

Romanovsky, V. E., Drozdov, D. S., Oberman, N. G., Malkova, G. V., Kholodov, A. L., Marchenko, S. S., Moskalenko, N. G., Sergeev, D. O., Ukraintseva, N. G., Abramov, A. A., Gilichinsky, D. A., and Vasiliev, A. A.: Thermal state of permafrost in Russia, Permafrost and Periglacial Processes, 21, 136-155, 2010a.

Romanovsky, V., Smith, S., and Christiansen, H.: Permafrost thermal state in the polar Northern Hemisphere during the international polar year 2007-2009: A synthesis, Permafrost Periglac., 21, 106-116, 2010b.

Sazonova, T., Romanovsky, V., Walsh, J., and Sergueev, D.: Permafrost dynamics in the 20th and 21st centuries along the East Siberian transect, J. Geophys. Res.-Atmos., 109, D01108, doi:10.1029/2003JD003680, 2004. 